\title{
Interaction of Indigo Carmine with Cetyltrimethylammonium Bromide and Application to Determination of Cationic Surfactant in Wastewater
}

\author{
Hong-Yan Wang, ${ }^{\dagger}$ Hong-Wen Gao, and Jian-Fu Zhao \\ State Key Laboratory of Pollution Control and Resources Reuse, School of Environmental Science \\ and Engineering, Tongii University, Shanghai-200092. P.R. Chind \\ ${ }^{\circ}$ Department of Chemistry and Biology, Suzhou Teachers College, Sushou-234000, P.R. China
}

Received Ma 28,2003

\begin{abstract}
The inicrosurface adsorption - spectral correction (MSASC) technique has been applied to the interaction of indigo carmine (IC) with cetyltrimethylammonium bromide (CTAB). The aggregation of IC on CTAB obeys Langmuir isothermal adsorption. The results show that both the monomer complex IC.CTAB and the micellar complex (IC.CTAB)- $x$ were formed. The binding constant of the monomer complex was calculated to be $\mathrm{K}_{\mathrm{IC} \times \mathrm{TAB}}=2.20 \times 10^{5} \mathrm{~L} \cdot \mathrm{mol}^{1}$, and the molar absorptivity of the micellar complex was calculated to be $\varepsilon_{[C \cdot C} \cdot \mathrm{TAB}^{7} 8^{560 \mathrm{~mm}}=8.58 \times 10^{5} \mathrm{~L} \cdot \mathrm{mol}^{1} \mathrm{~cm}{ }^{1}$. The aggregation was applied to the determination of cationic surfactant in wastewater.
\end{abstract}

Key Words : MSASC techniquc, Langmuir aggregation, Indigo carmine, Cetyltrimethylammonium bromide, Detcmination of cationic surfactant

\section{Introduction}

Surfactant is extensively used in our daily life and various industrial productions, for example in chemicals, oil, mineselecting, photosensitive materials, medicines, metallurgy and others. In many chemical analyses, a surfactant is often essential. Studies of surfactant solutions are still very active. ${ }^{l-1}$ The investigation into the interaction between a surfactant and a small molecule or ion is helpful to analyze the mechanism of surfactants in washing, emulsification, separation and synergism. Understanding the aggregation of a surfactant with other small molecules or ions is still very significant to synthesize the new types of efficient detergents. Some earlier models e.g. solubilization. stabilization and sensitization, micelle extraction, synergism perturbation," hydrogen bond formation, asymmetric microenvironment ${ }^{7}$ were proposed and applied to explain surfactant activity.

In the present work, the microsurface adsorption - spectral correction technique (MSASC) is described and applied to study the aggregation of indigo carmine (IC) on cetyltrimethylammonium bromide (CTAB). The structure of $\mathrm{IC}$ is given in Figure 1. It forms a bivalent anion in a wide $\mathrm{pH}$ range and is adsorbed on CTAB. The aggregation of IC on CTAB has been characterized. The maximal binding number

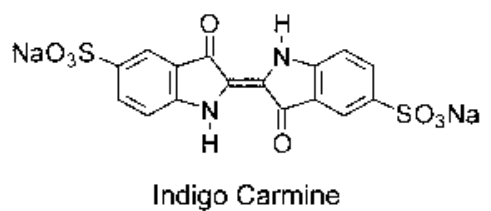

Figure 1. The molecular structure ol indigo carmine (IC).

\footnotetext{
"To whom correspondence should be addressed. E-mail: hwgao (ùmail.tongji.edu.cn
}

of IC on CTAB is $N=1$, and the adsorption constant is $\mathrm{K}_{\mathrm{C}} \mathrm{KAB}-\mathrm{CC}=2.20 \times 10^{5} \mathrm{~L} \cdot \mathrm{mol}^{-1}$ of the monomer complex. This aggregation has been applied to quantitative detection of cationic surfactant in wastewater with satisfactory results.

\section{Principle}

In a surfactant (S) solution, the aggregation of $S$ forms an electrostatic global micelle (Fig, 2, left) when the concentration of $S$ is greater than the critical micellar concentration (CMC). The electrostatic attraction of a negatively charged dye (L) occurs ${ }^{8.9}$ on the micellar microsurface until the kinetic equilibrium (Fig. 2, right) is reached. The electrostatic attraction results in the solubilization of $I$, in $S$ solution. Similarly, the same phenomenon happens on $S$

(1) surfactant (S) monomer

(here a cationic surfactant was used as representative)

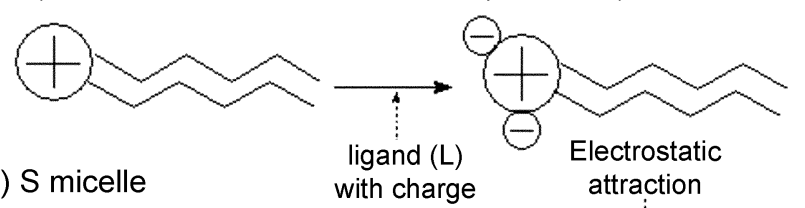

(2) S micelle
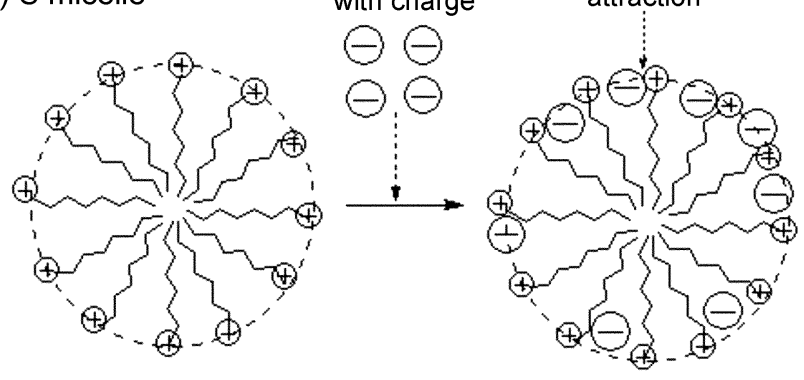

$S$ status in solution

Adsorption of $L$ on $S$

Figure 2. The aggregation of negatively charged dye (I.) on cationic surlactant (S): $1-S$ monomer and $2-S$ micelle. 
monomer (Fig. 2-1). The aggregation of $\mathrm{I}$, on $\mathrm{S}$ is only in a monolayer, like on a biomacromolecule. ${ }^{10.1 \mid}$ It obeys the l.angmuir isothermal adsorption. ${ }^{12}$ The S-I. solution equilibrium occurs as follows (m. $\mathrm{s}$, is microsurface phase.):

$$
\begin{array}{llccc} 
& \mathrm{L} & + & \mathbf{S}(\mathrm{m} . \mathrm{s} .) & \cdots \cdots-\mathrm{SL}_{\mathrm{n}} \text { (m.s.) } \\
\text { Initial state } & \mathrm{C}_{\mathrm{Lo}}\left(\mathrm{A}_{0}, \mathrm{~A}_{0}^{\prime}\right) & \mathrm{C}_{\mathrm{So}} & 0: \\
\text { Equilibrium } & \mathrm{C}_{\mathrm{L}} & 0 & \mathrm{C}_{\mathrm{S}_{0}}\left(\mathrm{~A}_{\mathrm{c}}\right)
\end{array}
$$

The langmuir isotherm equation is expressed as:

$$
\frac{1}{\gamma}=\frac{1}{N}+\frac{1}{K N C_{1}}
$$

where the symbol $K$ is the binding constant, and both $C$, and $C_{l i g}$ are the initial molarities of $\mathrm{S}$ and $\mathrm{L} . \mathrm{C}_{3}$ is the molarity of excess of $\mathrm{L}$ in equilibrium. The symbol $\gamma$ is the molar ratio of $\mathrm{L}$ adsorbed to $\mathrm{S}$. With an increase in $\mathrm{L}$ molarity, $\gamma$ approaches a maximal binding number, $N$. From plots $\gamma^{-1}$ ws. $\mathrm{C}_{1}{ }^{-1}, N$ and $K$ may be calculated. Both $C_{\%}$ and $\gamma$ are calculated by ineans of: $:^{11}$

$$
\begin{gathered}
\gamma-\eta \times \frac{C_{S .0)}}{C_{S(i)}} \\
C_{l .}=(1-\eta) C_{1.0}
\end{gathered}
$$

where

$$
\eta=\frac{A_{i} \cdot-\Delta A}{A_{\ell}}
$$

where the symbol $\eta$ indicates the effective fraction of $\mathrm{L}$ binding on $\mathrm{S} . A_{6}, A_{3}$ and $\Delta A$ are the real absorbance of the $\mathrm{S}$ $\mathrm{L}$ complex, the absorbance of $\mathrm{L}$ solution measured against water and that of the S-L solution measured against the reagent blank at a peak wavelength $\lambda_{2}+A_{c}$ is calculated by the relation: ${ }^{12}$

$$
A_{c}=\frac{\Delta A-\beta \Delta A^{\prime}}{1-\alpha \beta}
$$

where

$$
\alpha=\frac{\varepsilon_{S L}^{\lambda 1}}{\varepsilon_{S L}^{\lambda 2}}
$$

and

$$
\beta=\frac{\varepsilon_{L}^{\lambda 2}}{\varepsilon_{I}^{\lambda 1}}
$$

The symbol $\Delta \mathrm{A}^{\prime}$ indicates the absorbance of the $\mathrm{S}-\mathrm{L}$ solution measured against the reagent blank at the valley absorption wavelength $\lambda_{1}$. Both $\alpha$ and $\beta$ are the correction

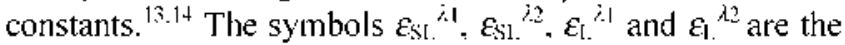
molar absorptivities of $\mathbf{S} \mathbf{L}$ and $\mathbf{L}$ at $\lambda_{1}$ and $\lambda_{2}$, respectively. In addition, the molar absorptivity (real $\varepsilon_{\mathrm{r}}{ }^{2 / 2}$ not apparent $\varepsilon_{\mathrm{a}}{ }^{\lambda 2}$ ) of the micellar complex is calculated by the relation:

$$
\varepsilon_{r} \cdot-\frac{m N A_{c}}{\delta \gamma C_{S}}
$$

where the symbol $\delta$ is the cell thickness (cm) and $m$ is the micelle aggregation number of $S$.

\section{Experimental Section}

Apparatus and reagents. Absorption spectra were recorded on a TU1901 Spectrophotometer (PGeneral, Beijing) and independent absorbance was measured on a Model 722 spectrophotometer, $\mathrm{pH}$ of solution was measured on an pHS-2C acidity meter (Leici Instruments, Shanghai). The temperature was adjusted and remained constant in a Model $116 \mathrm{R}$ electronic heated thermostatic bath, (Changiang Test lnstruments of Tongjiang, China).

The standard solution of CTAB $1.00 \mathrm{mmol} / \mathrm{l}$, was prepared by dissolving cetyltrimethylammonium bromide (CTAB) (A. R. Shanghai Chemical Reagents) in deionized water. IC solution $1.00 \mathrm{mmol} / \mathrm{L}$, was prepared by dissolving $0.5487 \mathrm{~g}$ of indigo carmine (content $85 \%$, Beijing Chemical Industry) in $1000 \mathrm{~mL}$, of deionized water. The Britton-Robinson buffer solutions (between $\mathrm{pH} \mathrm{1.8}$ and 9.62) were used to adjust the $\mathrm{pH}$ of the solution. $\mathrm{NaCl} 3 \mathrm{~mol} / \mathrm{L}$, was used for adjusting ionic strength of the solution and improve the reaction sensitivity. The masking reagent was prepared by mixing $100 \mathrm{~mL}$ of $5 \% \mathrm{Na}-\mathrm{F}$.DTA, $100 \mathrm{ml}$ of $2 \%$ ethylenediamine and $100 \mathrm{ml}$. of $5 \%$ potassium sodium tartrate, and it was used for masking metal ions in the sample.

\section{Recommended procedures.}

Aggregation of 1C on CTAB: Into a $25 \mathrm{ml}$. calibrated flask, an appropriate working solution of CTAB, $2.5 \mathrm{ml}$. of Britton-Robinson buffer solution, $5 \mathrm{ml}$. of $3 \mathrm{~mol} / \mathrm{l} . \mathrm{NaCl}$ and $1.00 \mathrm{ml}$. of $\mathrm{lC}$ solution were added. The solution was diluted to $25 \mathrm{~mL}$, with deionized water and mixed thoroughly, After $10 \mathrm{~min}$, the absorbances were measured at 560 and $610 \mathrm{~nm}$. respectively, against a reagent blank treated in the same way without CTAB.

Preparation and analysis of samples: Two wastewater samples were analyzed: $\# 1$ from the Huaihe River and $\$ 2$ from a local sewage pipe. A milliliter of the standard solution of C IAB was added to the samples $(100 \mathrm{~mL})$ before coloring. $10.0 \mathrm{~mL}$ of a sample was taken in a $25 \mathrm{~mL}$ flask. $0.5 \mathrm{~mL}$ of the masking reagent was added. The successive operations were carried out according to the above procedure.

\section{Results and Discussion}

Spectral analysis. The $\mathrm{IC}-\mathrm{C} I \mathrm{AB}$ binding reaction solution was measured and the absorption spectra of $\mathrm{IC}$ and its $\mathrm{C} \mathrm{I} \mathrm{AB}$ solutions are shown in Figure 3. By comparing spectrum 3 with 4 , we found that the addition of $\mathrm{NaCl}$ could sensitize the binding reaction. From spectra $\mathrm{I}$ and 2 , we observed that the spectral peak of the complex is located at $560 \mathrm{~nm}$ and that of IC at $610 \mathrm{~nm}$. The peak blue shift of the complex was $50 \mathrm{~nm}$. Such a great wavelength-shift is rare in similar systems. ${ }^{8.911}$ Are findings indicates that the $\mathrm{IC}-\mathrm{C}$. IAB binding is firm in spite of the electrostatic attraction. Nevertheless. ordinary spectrophotometry is still unfit for characterization of the IC-CIAB aggregation because the resolution of 


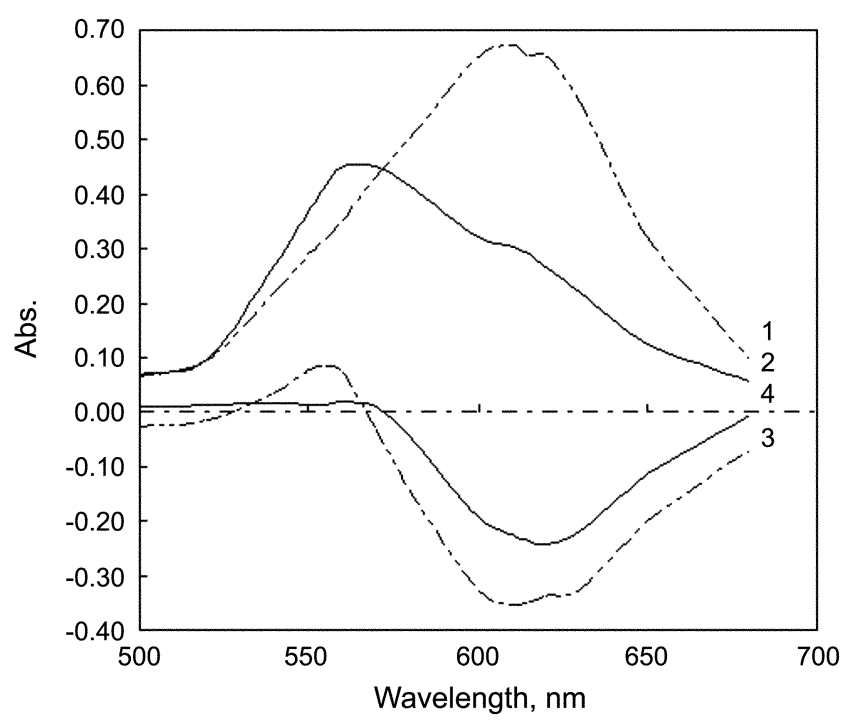

Figure 3. Absorption spectra of IC and its CTAB solutions containing $0.6 \mathrm{~mol} / \mathrm{I}$. NaCl: I- IC ( 1.00 , 4 mol $25 \mathrm{~mL}$ ) solution against water. $2-\mathrm{IC}(1.00 \mu \mathrm{mol} / 25 \mathrm{~mL})-\mathrm{CTAB}(10 \mu \mathrm{mol} / 25 \mathrm{~mL})$ solution against water. which does not contain free IC. 3- IC (1.00 mmol $25 \mathrm{ml})$ - CTAB (1.00 $\mu$ mol $25 \mathrm{~mL}$.) solution agairst a reagent blank and $4-$ same as 3 but in absence of $\mathrm{VaCl}$.

spectra is not high enough. From spectrum 3, the peak of the IC-CTAB solution is located at $560 \mathrm{~nm}$, and its valley is at $610 \mathrm{~nm}$. Such two wavelengths were used. From spectra 1 and 2, the correction constants were calculated to be $\beta$ $=0.523$ and $\alpha=0.500$, so $\mathrm{A}_{i}=1.44\left(\Delta \mathrm{A}-0.523 \Delta \mathrm{A}^{\prime}\right)$. $\mathrm{A}_{\mathrm{c}}$ was used for calculating the real absorbance of the IC-CTAB complex in the mixed solution.

Effect of $\mathbf{p H}$. Absorbance of the IC-CTAB solutions was measured for a variety of $\mathrm{pH}$ values, $\gamma$ is shown in Figure 4 . We could not see any change in the binding ratio as the $\mathrm{pH}$ increased. This particular dye has two very strong acid groups $\left(-\mathrm{SO}_{3} \mathrm{H}\right)$. CTAB structure will not change an,d $\mathrm{IC}^{2-}$ can be formed between $\mathrm{pH} 1.8$ to 9.62 . This is the reason for

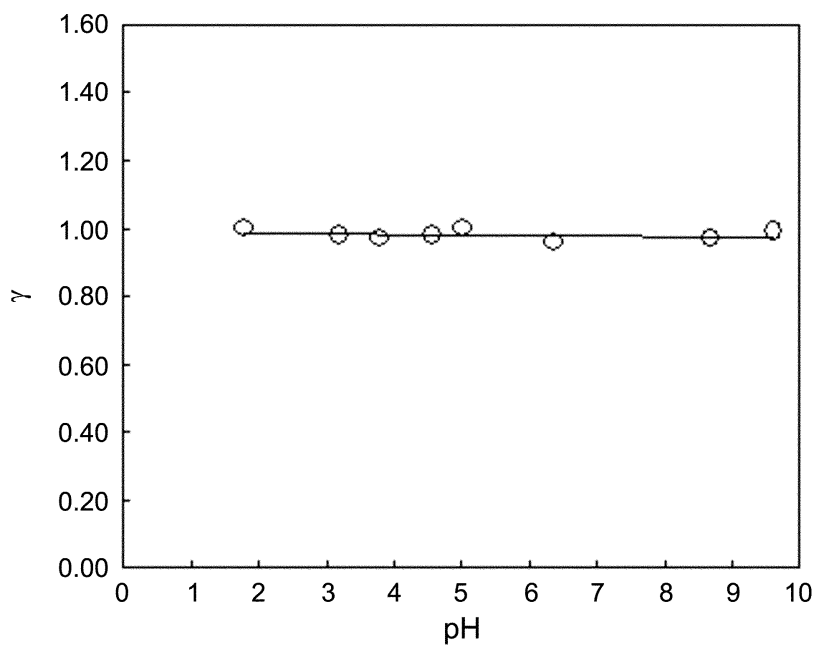

Figure 4. Fflect of $\mathrm{pH}$ on $g$ of the solutions containing $1.0 \mu \mathrm{mol}$ $16 / 25 \mathrm{ml}$. and 1.00 amol ClAls $/ 25 \mathrm{ml}$ and pll belween 1.8 and 9.62 .

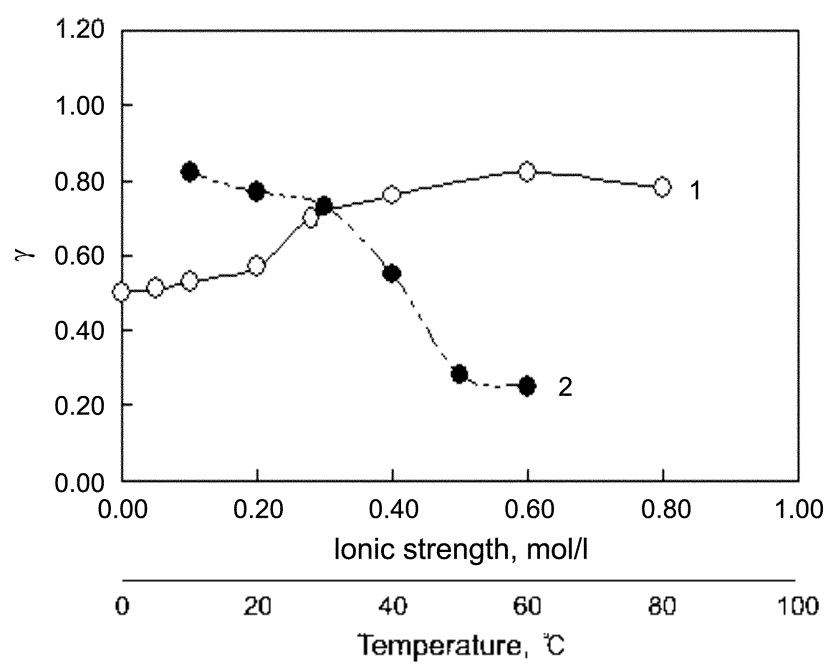

Figure 5. Efficet of the operation conditions on $\gamma$ of the solutions containing $1.0 \mu \mathrm{mol} I \mathrm{C} / 25 \mathrm{ml}$. and $1.00 \mu \mathrm{mol}$ C.TAB $25 \mathrm{~mL}: \mathrm{I}$ ionic strength and 2- lemperalure.

keeping $\gamma$ as a constant. In this work, pH 5.02 buffer solution was added.

Effect of ionic strength, temperature and time. To investigate the effect of ionic strength on aggregation of $\mathrm{IC}$ on CTAB, we added $\mathrm{NaCl}$ to the solution, and its effect on $\gamma$ is shown in Figure 5. We observed that $\gamma$ heightens slowly when the ionic strength is less than $0.2 \mathrm{~mol} / \mathrm{L}, \gamma$ increases and then remains a constant when the ionic strength is more than $0.2 \mathrm{~mol} / \mathrm{L}$. This is the reason for the firm binding between IC and CTAB. In addition, the addition of inorganic salt results in an obvious decrease in CMC of the ionic surfactant, and the CTAB micelle has a higher attraction microsurface than the CTAB monomer. Therefore, the presence of $\mathrm{NaCl}$ can sensitize the IC-CTAB binding reaction. In this work, $0.6 \mathrm{~mol} / \mathrm{l}, \mathrm{NaCl}$ was added (to what??).

The effect of temperature on $\gamma$ is shown in Figure 5. $\gamma$ decreased significantly with an increase in the temperature over $30^{\circ} \mathrm{C}$. The electrostatic attraction among molecules is destroyed easily in a high temperature environınent ${ }^{9.10}$ because the binding strength of the electrostatic attraction is always much less than that of a chemical bond. Besides, an increase in temperature results in an increase in the CMC of $\mathrm{S}$ more than to a decrease the attraction microsurface of $\mathrm{S}$. Ihis is in accordance with the objective nature of surface adsorption.

The effect of the reaction time on $\gamma$ indicates that the aggregation of $\mathrm{IC}$ on $\mathrm{C} / \mathrm{IAB}$ is very rapid at $10^{\circ} \mathrm{C}$. The color fading appears in $20 \mathrm{~min}$. This is attributed to the fact that the aggregation of IC on CIAB causes the formation of flocculate in solutions of high ionic strength. The measurement of absorbance of the solutions should be carried out within 10 min of the formation of the flocculent. (Check!)

Characterization of the IC-CTAB interaction. By varying the addition of $1.00 \mathrm{mmol} L \mathrm{~L} I \mathrm{C}$, the $\mathrm{IC}-\mathrm{C}$. solutions were measured, and absorbance change is shown in Figure 6. From curve $3, A_{c}$ approaches a maximum when 


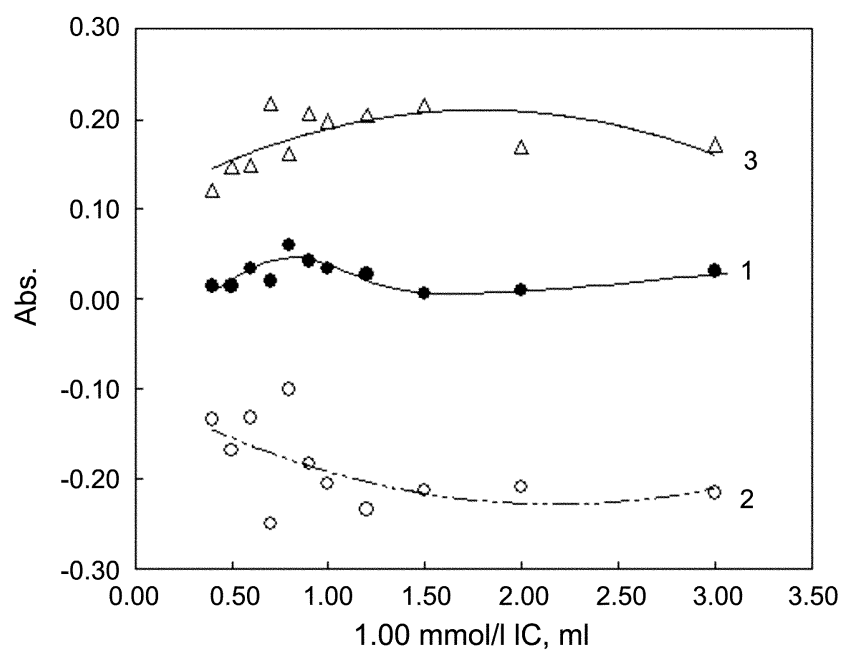

Figure 6. Lffect of [C on the absorbance of the solutions containing $0.500 \mu \mathrm{mol}$ CTAB $25 \mathrm{~mL}$ : I- measured against reagent blank at $560 \mathrm{~nm}$. 2- same as 1 but at $610 \mathrm{~mm}$ and 3 -calculated $A_{L}$.

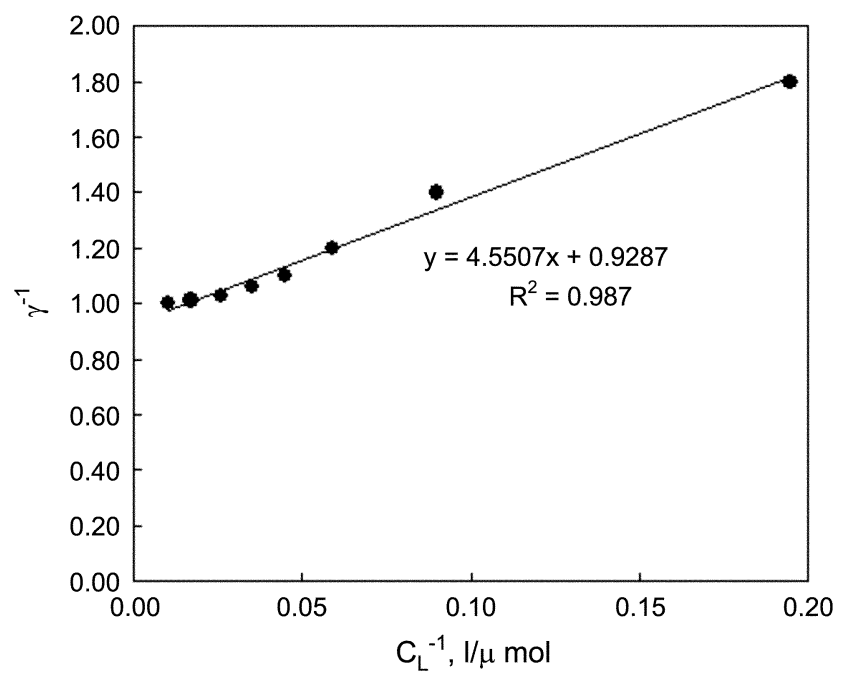

Figure 7. Plots $\gamma^{-1}$ vs. $\mathrm{C}_{\mathrm{L}}^{-1}$.

the addition of $\mathrm{IC}$ solution is between 0.9 and $1.5 \mathrm{~mL}$. In the quantitative detection of cationic surfactant, $1.2 \mathrm{~mL}$ of 1.00 mınol/ $L$ IC was added. Both $\gamma$ and $C_{L}$ of each solution were calculated. Their relationship is shown in Figure 7. Due to the linear plots $\gamma^{-1}$ vs. $\mathrm{C}_{\mathrm{L}}^{-1}$, the adsorption of $\mathrm{IC}$ on $\mathrm{C}$ [AB obeys the Langmuir isothermal adsorption. from the intercept, the maximal binding number of $I C$ on $\mathrm{CIAB}$ is calculated to be $N=1$. Therefore, the monomer complex $I C$ C IAB is formed. We estimated that the large micellar complex, $\left(\mathrm{IC} \cdot \mathrm{C}[\mathrm{AB})_{-} \mathrm{s}\right.$, is formed only when the concentration of $\mathrm{C}$ IAB is more than its $\mathrm{CMC}$ at $0.96 \mathrm{mmol} / \mathrm{L}$ and sufficient $\mathrm{IC}$ exists in the solution. From the linear slope, the binding constant of complex $[\mathrm{C} \cdot \mathrm{C}$ [AB was calculated to be $K=$ $2.20 \times 10^{5} \mathrm{~L}_{\mathrm{mol}} \mathrm{m}^{-1}$. For the determination of the binding constant of a complex, the MSASC technique has special advantages in operation and principle by comparing with the classical method, such as the Pesavento model. ${ }^{1.5}$ continuous variations. $^{160}$

In addition, $\eta$ of $\mathrm{IC}$ in the solutions, as shown in figure 8 ,

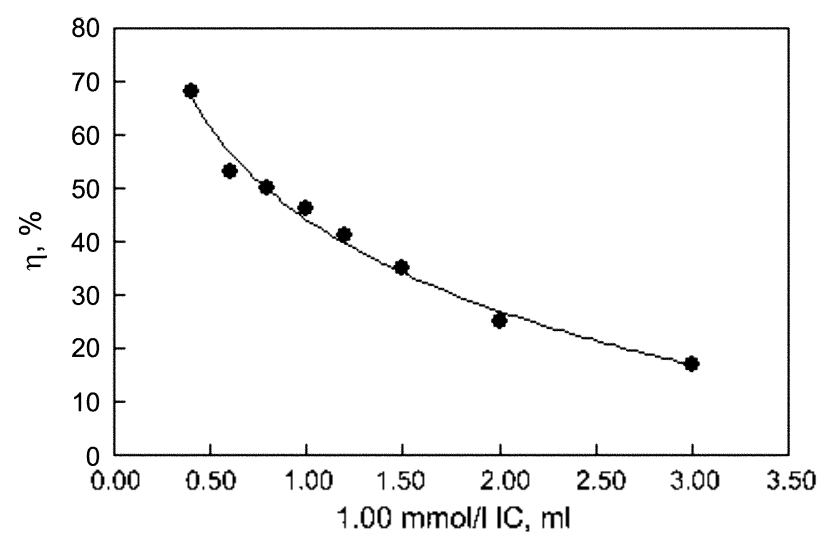

Figure 8. Change of $\eta$ with $\mathrm{lC}$. where the solutions contained 0.500 atmol CTAB/ $25 \mathrm{~mL}$.

$\eta$ is only $40 \%$ with the addition of $1.2 \mathrm{~mL}$ of $1.00 \mathrm{mmol}$ I, IC. The free IC in equilibrium approaches $60 \%$. Therefore, so much free IC no doubt seriously affects the measurement of real absorbance of the complex. The real (not apparent) molar absorptivity of the micellar complex was calculated to be $\varepsilon_{\mathrm{IC}} \cdot \mathrm{CTAB}^{560 \mathrm{~mm}}=8.58 \times 10^{5} \mathrm{~L} \cdot \mathrm{mol}^{-1} \cdot \mathrm{cm}^{-1}$.

Determination of cationic surfactants.

Calibration graph and precision: The standard series of CTAB solutions was prepared and measured, using $1.2 \mathrm{ml}$. of $1.00 \mathrm{mmol} / \mathrm{L}$, IC. The calibration graph is shown in Figure

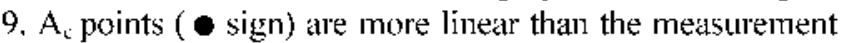
points ( ${ }^{2}$ sign) and curve 2 has a much higher slope than that of curve 1. Therefore, the spectral correction technicjue has higher sensitivity and better accuracy than single wavelength spectrophotometry. Three times the standard deviation (SD) of fifteen replicated determinations of the reagent blanks was used to calculate the detection limit of cationic surfactant to be $1.0 \mu \mathrm{g} / \mathrm{mL}$. Six replicated determinations of $0.500 \mu \mathrm{mol}$ of standard CTAB revealed the average concentration was $0.511 \pm 0.010, a m o l$ and the relative standard deviation (RSD) was $2.0 \%$.

Effect of foreign ions: By adding the masking reagent to

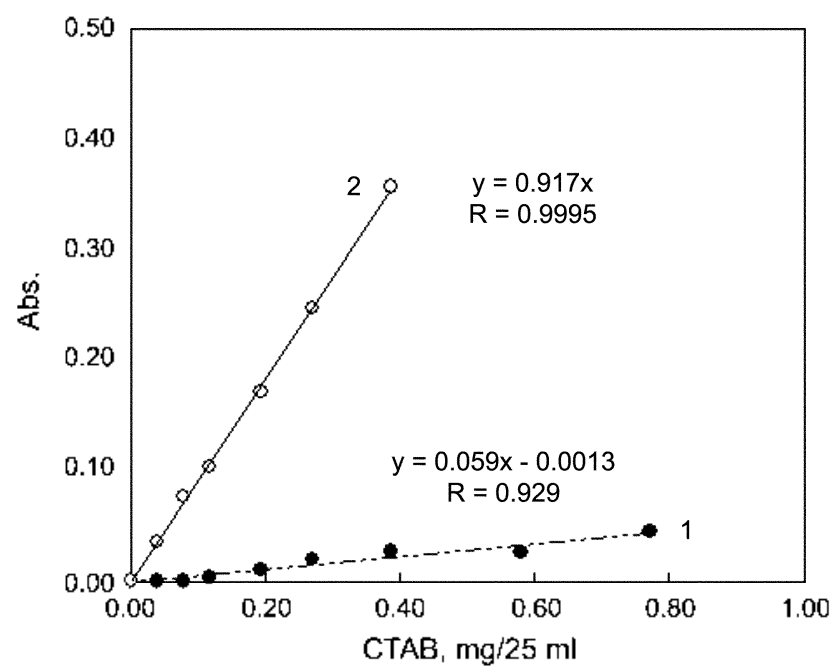

Figure 9. Standard curves for the determination of cationic surfactant: 1- $\triangle \mathrm{A}$ mcasured at $560 \mathrm{~nm}$ and 2- $A_{c}$. 
Table 1. Detenmination of cationic surfactant in wastewater

\begin{tabular}{ccc}
\hline Sample No. & Added & CTAB, Found $(\mathrm{mg})$ \\
\hline \multirow{2}{*}{ \#\# } & $15 \mathrm{~mL}$ of the sample & $0.031 \pm 0.0017$ \\
& & RSD: $5.3 \%$ \\
\cline { 2 - 3 } & $0.100 \mathrm{~m}$ m of CTAB & $0.136 \pm 0.007$ \\
& $+15 \mathrm{~mL}$ of the sample & Rec.: $105 \%$ \\
\hline $2 \#$ & $5.00 \mathrm{~mL}$ of the sample & $0.016 \pm 0.001$ \\
& & RSD: $6.2 \%$ \\
\cline { 2 - 3 } & $0.200 \mathrm{~m}$ mo of CTAB & $0.206 \pm 0.006$ \\
& $+5 \mathrm{~mL}$ of the sample & Rec: $95.0 \%$ \\
\hline
\end{tabular}

the procedure, the influence of foreign ions and substances was investigated. None of the following ions and compounds affected the direct determination of $0.500 \mu \mathrm{mol}$ of $\mathrm{CTAB}$ (less than $10 \%$ erтor): $\mathrm{I}$ mg of $\mathrm{K}^{-}, \mathrm{Ca}^{2-}, \mathrm{F}^{-}, \mathrm{SO}_{4}^{2-}, \mathrm{Ac}^{-}$. $\mathrm{NO}_{3}^{-}, \mathrm{Mg}^{2+}, 0.5 \mathrm{mg}$ of $\mathrm{NH}_{4}^{+}, \mathrm{I}^{-}, \mathrm{PO}_{4}^{3-}, \mathrm{C}_{3} \mathrm{O}_{4}{ }^{2-}$, glucose. amino acid, acetone. ethanol, SDS; $0.2 \mathrm{mg}$ of $\mathrm{Al}(\mathrm{III}) \mathrm{Ba}(\mathrm{II})$. $\mathrm{Mn}(\mathrm{II}) . \mathrm{Zn}(\mathrm{II}) . \mathrm{Pb}(\mathrm{II}) ; 0.1 \mathrm{mg}$ of $\mathrm{Cu}(\mathrm{II}), \mathrm{Ni}(\mathrm{II}), \mathrm{Co}(\mathrm{II})$. $\mathrm{Cd}(\mathrm{II})$. $\mathrm{Fe}$ (III). $\mathrm{Be}$ (II) and $0.05 \mathrm{mg}$ of $\mathrm{Hg}$ (II).

\section{Conclusions}

The deternination of cationic surfactant in wastewater was made and the results are summarized in Table I. The recovery of CTAB is between 95.0 and $105 \%$. and the RSD is less than $6.2 \%$.

The MSASC technique provides a very useful experimental strategy for the study of the physico-chemical interaction among molecules. This work and some earlier systems ${ }^{8.917}$ all indicate the binding of $L$ with $S$ originating from an electrostatic attraction between $S$ and an oppositely charged $\mathrm{L}$ not from a chemical bond. This provides a new way to analyze why surfactants can be used extensively in many industries and applications common to daily life. Though the IC-CTAB binding reaction is applied to only the macro analy sis of cationic surfactant, its simplicity and accuracy may remind us of and point the way toward new and sensitive spectrophotometric methods for trace analy sis.

\section{References}

1. Knaebel. A.: Oda. R. Langmir 2000. 16. 2489.

2. Urata. K.: Takaishi. N. J. Surf. Deterg. 2001. f. 191.

3. Oda, R: Huc. I.: Candau. S. J. Chen Conmm. 1997, 2105.

4. Sehgal, P.; Doe. H.; Batishi, M. S. J. Sirf. Deterg. 2002, 5. 123.

5. Ci. Y. X.: Yang. M. M. Chin. Sci. Bull. 1983. 16. 980.

6. Zheng. Y. X.: Li. L. D.: Sun. S. Q. Chin. J. Chem. Reagents 1984. 6.273 .

7. Qi. W. B: Zhu. L. Z. Chent J. Chm Lni: 1986, 7,407.

8. Gao. H. W. Hu, N. L. J. Solution Chent 2002. $31,165$.

9. Gao, H. W. Yang. J. X. Colloids Surf. A 2002, 205. 283.

10. Gao. H. W.: Yang. T. X.: Tiang. T.: Yu. L. Q. Supramol. Chem. 2002. 14.315

11. Gao. H. W.: Xu. W. Q. Anal. Chim Acta 2002. 458.417.

12. Langmuir. I. J. Am. Chem. Soc. 1918. 10, 1361.

13. Gao. H. W. Bull. Korean Chent. Soc. $2012,23.943$.

14. Gao. H. W: Zhao, J. F. Aust. J. Chem 2002. 55. 767.

15. Pesavento. M.: Profumo. A. Talanta 1991. 38. 1099.

16. Likussar. W. Anal. Chem 1973. 45. 1926.

17. Gao. H. W.: Ye. Q. S.: Liu. W. G. Anal Sci. 2002. 18.455. 